\title{
International Journal of Oceanography \& Aquaculture
}

\section{Aquaculture in India, the Second Largest Producer of Farmed}

\author{
Fish
}

\begin{abstract}
Dinakaran Michael R*
Vels Institute of Science, Technology and Advanced Studies (VISTAS), Vels University, Pallavaram, Chennai-600117, India
\end{abstract}

*Corresponding author: Dinakaran Michael R, Dean of Life Sciences, Vels Institute of Science, Technology and Advanced Studies (VISTAS), Vels University, Pallavaram, Chennai-600117, India, Tel: 98421-68018; Email: deansls@velsuniv.ac.in

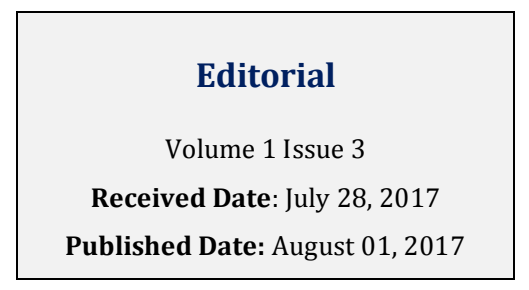

\section{Editorial}

I am happy to give a brief report on status of aquaculture in India to the audience of International Journal of Oceanography \& Aquaculture (IJOAC). Authentic sources now place India as the second largest producer (after China) of farmed fish. However, this ranking is not significant because India contributes only $6.3 \%$ of the total aquaculture produce worldwide. On the other hand, China holds a lion's share $(61.7 \%)$ of world aquaculture produce [1]. Interestingly, India is having great potential to claim a position closer to China with a coastline of $7,517 \mathrm{~km}$ and an estimated 2.36 million hectares of tanks, ponds etc. available for aquaculture. If one must include paddy fields and agricultural areas where aquaculture can be done, the estimate can go higher. The climatic and environmental conditions prevailing in India is so diverse that it is possible to raise diverse fish such as trout (cold water species) and tilapia (tropical species). Another interesting fact about India is that Indians consume nearly almost all the finfish (mostly carps) they produce. Prawns and shrimps especially vannamei species, are the most exported aquaculture products. Farmed fish contributes about $5 \%$ to the national agricultural GDP. In India, more than 14 million people are involved in fishing and aquaculture activities [2]. It is obvious that responsibilities were carefully bifurcated between fishermen and women. While men take care of the production, women are fairly responsible for marketing the produce.

As with other countries, India started facing protests against aquaculture as early as 1995 when the Supreme Court ordered demolition of shrimp farms set up within 500 meters of coastal line and alongside back waters, rivers etc. and banned establishment of new shrimp farms in three coastal states in India. Even before its large scale farming, Mozambique tilapia (Oreochromis mossambicus) was banned in 1959 due to ecological concerns. Most scientists believe that unfortunately, the variety of Mozambique tilapia introduced was a very slow growing one and so not preferred for farming by fish farmers. Being an omnivorous and sturdy species M. tilapia sustained itself and spread all over and that arguably, led to destruction of biodiversity of many large water bodies such as Vaigai and Bhavani sagar river systems in south India. One of the worst hit was Jaisamand Lake, in Rajasthan state where native species like Tor tor and $T$. putitora nearly faced extinction. For this reason, till recently, this act of introducing tilapia into large, unrestricted water body was criticized by many scientists all over India. Tilapia again struck terror during 1970s when Nile tilapia (O. niloticus), a world renowned species, was introduced. Due to lack of regulation, everybody had a free hand to transport and dump the fish anywhere. This time, the damage was even more poignant. The Ganges and the Yamuna, the largest river systems in India was hit. According to 2007 statistics, $3.5 \%$ of all the fish found in the Yamuna River were Nile tilapia and 7\% of all in the Ganges. When the native species are threatened, the government of India came out with regulating tilapia aquaculture. These regulations were followed by enormous fund flow in favour of research and development of new and safe aquaculture techniques.

Despite these hue and cry against tilapia, there are also some scientists who believe, in the context of large scale culturing of tilapia in most of the countries, that this 


\section{International Journal of Oceanography \& Aquaculture}

resistance to tilapia introduction in India was mostly due to a powerful pro (major) carp lobby at national decision making level. One of the earliest success stories is that of Version Chemicals and distilleries Company at Chennai, Tamil Nadu which pioneered in mono-sex culture of tilapia. New breeding technologies and concerted efforts by scientists across the globe helped in the production of robust and fast growing strains like GIFT tilapia, Chitralada strain etc. Globally, tilapia is the second largest produced and consumed fish after carps. Perhaps, Tilapia can be the only finfish which can be exported from India to North America and Europe as many other countries do. Its widespread attraction, flavor and taste (as recently as yesterday, I enjoyed a couple of large fillets of tilapia in IHOP, a popular American restaurant in Ashburn, VA!) earned it a pet name called 'aquatic chicken'. I personally consider it is high time that government of India promoted the culture of tilapia in a big way in this country to increase the economic standards of fish farmers [3].

In the recent past there has been huge outcry against the use of chemotherapeutics in aquaculture all over the world. India also faced significant threat upon indiscriminate use of antibiotics and other chemotherapeutics. However, due to the growing pressure put by importers, antibiotics use is greatly minimized nowadays. Hence I find it is sensible to impress upon the use of immuno prophylactics like vaccines and immuno stimulants in Indian aquaculture industry.

Till now, no known vaccines are marketed or used in India despite the fact that market attractiveness is very high [4]. Fish farmers are very much aware of the likeliness of disease occurrence in their farms and are capable enough to identify the causative agent but they are handicapped by the unavailability of effective vaccines. This leads to loss of crop to disease despite available prophylactic measures. I invite fish immunologists and entrepreneurs to concentrate on development and marketing of affordable and efficacious multivalent (protecting against many diseases) fish vaccines in India which are very important to reduce the disease loss in fish culture in this country and elsewhere. Norway which is pioneer in fish vaccination started vaccinating all the fish against furunculosis by the year 1980. In the year 1994, total use of antibiotics in Norwegian aquaculture farms was substantially reduced. Norwegian fish farmers believe that vaccination along with good culture practices are better than the use of antibiotics. Sommerset, et al. 2005 [5] reviewed some of the commercially available vaccines worldwide. It is interesting to note that only developed countries are interested in developing vaccines and not many noteworthy vaccines are developed and available in Asian countries which collectively produce more than $85 \%$ of global farmed fish. Vaccine against Streptococcus iniae for tilapia is the only available commercial vaccine in Asian countries. Despite being world number one in aquaculture, in China there is no practical application of vaccination reported [6].

Immunostimulants are inexpensive yet reasonably effective alternatives to vaccines. They can be mixed with feed and can be administered easily. Some of the commercial immuno-stimulants like MacroGard $^{\text {TM }}$ are available in India. However, their use is not widespread. India is also a huge repertoire of ethnobotanical knowledge. It is high time that this knowledge was shared in order to design a cost-effective, biodegradable immunostimulants that can make Indian aquaculture sector, a huge success.

Let me complete the editorial with the simple message, "Come on everybody connected with aquaculture! Together let us all think locally and act globally for the responsible and sustainable development of global aquaculture to meet the huge (healthy) protein requirement of the teeming millions of people in the coming centuries".

\section{References}

1. FAO 2014 report (2014) The State of World Fisheries and Aquaculture. Food and agriculture organization of the United Nations Rome.

2. The Economic Times (2017) Indian aquaculture shrimp production crosses 5 lakh tonnes. ET Bureau. Updated: May 14, 01.50 PM IST.

3. Jelte de Jong (2017) Aquaculture in India. Rijksdienst voor Ondernemend Nederland.

4. Mahendra Kumar Pallapothu (2013) Analysis and evaluation of market attractiveness for fish vaccines in Indian aquaculture industry. Interdisciplinary journal of contemporary research in business 4(9): 479-494.

5. Sommerset I, Krossøy B, Biering E, Frost P (2005) Vaccines for fish in aquaculture. Expert Rev Vaccines 4(1): 89-101.

6. Brudeseth BE, Wiulsrød R, Fredriksen BN, Lindmo K, Løkling KE, et al. (2013) Status and future perspectives of vaccines for industrialised fin-fish farming. Fish Shellfish Immunol 35(6): 1759-1768. 